\title{
Nanostructure and photocatalytic behavior of glass-ceramics in $\mathrm{Bi}_{2} \mathrm{O}_{3}-\mathrm{Nb}_{2} \mathrm{O}_{5}-\mathrm{Li}_{2} \mathrm{O}-\mathrm{B}_{2} \mathrm{O}_{3}-\mathrm{SiO}_{2}$ system
}

\author{
OhHyeok KWON ${ }^{1 \dagger}$, , Yoshihiro TAKAHASHI ${ }^{1}$, Takamichi MIYAZAKI ${ }^{2}$, \\ Nobuaki TERAKADO ${ }^{1}$ and Takumi FUJIWARA ${ }^{1, *}$ \\ ${ }^{1}$ Department of Applied Physics, Graduate School of Engineering, Tohoku University, \\ 6-6-05 Aoba, Aoba-ku, Sendai 980-8579, Japan \\ ${ }^{2}$ Department of Instrumental Analysis, Graduate School of Engineering, Tohoku University, \\ 6-6-11 Aoba, Aoba-ku, Sendai 980-8579, Japan
}

\begin{abstract}
We have prepared a multicomponent glass, in which photocatalytic $\mathrm{Bi}_{2} \mathrm{O}_{3}-\mathrm{Nb}_{2} \mathrm{O}_{5}$ and $\mathrm{Bi}_{2} \mathrm{O}_{3}-\mathrm{SiO}_{2}$ phases are crystallizable, and have examined the nanometric structure and photocatalytic activity in the resulting glassceramics (GCs). The GCs crystallized the $\mathrm{Bi}_{3} \mathrm{NbO}_{7}$ nanophase followed by the $\mathrm{Bi}_{5} \mathrm{Nb}_{3} \mathrm{O}_{15}$ nanophase as increasing the heat-treatment temperature, and eventually, the nano-sized $\mathrm{Bi}_{5} \mathrm{Nb}_{3} \mathrm{O}_{15}-\mathrm{Bi}_{4} \mathrm{Si}_{3} \mathrm{O}_{12}$ co-crystallized GC sample was obtained. Although photocatalytic activity was confirmed in the singly $\mathrm{Bi}_{3} \mathrm{NbO}_{7^{-}} / \mathrm{Bi}_{5} \mathrm{Nb}_{3} \mathrm{O}_{15^{-}}$ crystallized samples by means of the degradation test of rhodamine B dye, a higher activity was found in the cocrystallized sample. The high photocatalytic activity was considered in accordance with a nanometric structural observation.

(2020 The Ceramic Society of Japan. All rights reserved.
\end{abstract}

Key-words : Glass-ceramics, Photocatalyst, Crystallization, Glass

[Received May 22, 2020; Accepted July 22, 2020]

Photocatalyst that enables us to obtain the hydrogengeneration and water-purification by sunlight is a potential technology in our sustainable life and infection prevention. Nevertheless, its practical applications have been limited due to the inherent drawbacks such as recombination of hole-electron pairs, chemical stability, and so on. In order to improve the photocatalytic activity, aspects of material science/physics, e.g., the fabrication processing and morphology control, are necessary, and are quite significant for efficient and extensive utilization of photocatalyst.

Recently, bismuth-based oxides have absorbed much attention for photocatalytic material because of the narrow band gap compared with other oxides due to the hybridized $\mathrm{Bi}-6 \mathrm{~s}$ and $\mathrm{O}-2 \mathrm{p}$, leading us to expect the response with visible light. For example, in $\mathrm{Bi}_{2} \mathrm{O}_{3}-\mathrm{Nb}_{2} \mathrm{O}_{5}$ system, $\mathrm{Bi}_{3} \mathrm{NbO}_{7}$ crystal with an oxygen-deficient fluorite structure possesses the band gap of $E_{\mathrm{g}} \sim 2.7 \mathrm{eV},{ }^{1)}$ which is smaller than that of $\mathrm{TiO}_{2}(\sim 3.2 \mathrm{eV})$. In addition, band gap of $\mathrm{Bi}_{5} \mathrm{Nb}_{3} \mathrm{O}_{15}$ crystal with a mixed layered Aurivillius phase structure is found to be $E_{\mathrm{g}} \sim 2.90 \mathrm{eV}^{2)}$ These bismuth niobate are largely expected to show a photocatalytic activity under sunlight. The compounds in $\mathrm{Bi}_{2} \mathrm{O}_{3}-\mathrm{SiO}_{2}$ system, e.g., $\mathrm{Bi}_{2} \mathrm{SiO}_{5}, \mathrm{Bi}_{12} \mathrm{SiO}_{20}$, and $\mathrm{Bi}_{4} \mathrm{Si}_{3} \mathrm{O}_{12}$, have

\footnotetext{
Corresponding author: O. Kwon; E-mail: kwon.ohhyeok. p8@dc.tohoku.ac.jp

* Corresponding author: T. Fujiwara; E-mail: fujiwara@ laser.apph.tohoku.ac.jp
}

reported to be a candidate for photocatalyst as well, ${ }^{3)-5)}$ and particularly, nanostructured $\mathrm{Bi}_{4} \mathrm{Si}_{3} \mathrm{O}_{12}$ phase is demonstrated to show the excellent performance. ${ }^{6}$ )

Our research group has suggested a strategy for fabrication of novel photocatalytic material by utilization of glass-ceramic (GC) processing, which is suitable both for production of massive material and for control of the nanometric structure, toward hydrogen-plant application. ${ }^{7), 8)}$ Although there are some reports for GC materials showing photocatalytic activity so far, ${ }^{9)-11)}$ their active phases are singly-crystallized in the materials as well as our GC samples. In order to achieve a high performance GC-photocatalyst, crystallization of multiple photocatalytic phases is deemed to be effective in the GC material. Therefore, we have prepared a multicomponent precursor glass, in which photocatalytic $\mathrm{Bi}_{2} \mathrm{O}_{3}-\mathrm{Nb}_{2} \mathrm{O}_{5}$ and $\mathrm{Bi}_{2} \mathrm{O}_{3}-$ $\mathrm{SiO}_{2}$ phases are co-crystallizable, and have examined the phase formation and crystallized nanostructure in the resulting GCs. The photocatalytic properties have been also assessed.

Functional crystalline phases, which are intended to precipitate in GCs, are desirable to totally (or partially) consist of glass-forming/intermediate oxides from the viewpoint of preparation of the precursor. In this study, we have prepared the $18.75 \mathrm{Bi}_{2} \mathrm{O}_{3}-6.25 \mathrm{Nb}_{2} \mathrm{O}_{5}-18.75 \mathrm{Li}_{2} \mathrm{O}-$ $37.5 \mathrm{~B}_{2} \mathrm{O}_{3}-18.75 \mathrm{SiO}_{2}$ glass (in mol\%) that corresponds to the photocatalytic $\mathrm{Bi}_{2} \mathrm{O}_{3}-\mathrm{Nb}_{2} \mathrm{O}_{5}$ and $\mathrm{Bi}_{2} \mathrm{O}_{3}-\mathrm{SiO}_{2}$ phases added with a glass-forming $\mathrm{Li}_{2} \mathrm{~B}_{4} \mathrm{O}_{7} . \mathrm{Bi}_{2} \mathrm{O}_{3}$ and $\mathrm{Nb}_{2} \mathrm{O}_{5}$ are 
also selected as constituents of precursor glass frequently because they also contribute to the network structure: ${ }^{12)-14)}$ The as-quenched precursor was obtained by means of a conventional melt-quenching method. The chemical reagents of $\mathrm{Bi}_{2} \mathrm{O}_{3}, \mathrm{Nb}_{2} \mathrm{O}_{5}, \mathrm{SiO}_{2}$, and $\mathrm{Li}_{2} \mathrm{~B}_{4} \mathrm{O}_{7}$ powders are mixed by an alumina mortar, and the mixture was melted in a platinum crucible at $1100^{\circ} \mathrm{C}$ for $15 \mathrm{~min}$ in air atmosphere. We have confirmed by an X-ray diffraction (XRD; $\mathrm{Cu}-\mathrm{K} \alpha$ ) analysis that the as-quenched precursor indicated a halo pattern, meaning a glassy state without long-range ordering. Crystallization behavior and thermal property of the precursor glass were studied by means of a differential thermal analysis (DTA) at heating rate of $10 \mathrm{~K} / \mathrm{min}$. The precursor glass was subjected to isothermal heat-treatment at different temperatures for $30 \mathrm{~min}$ in air to obtain the GC samples. Phase formation and its morphology in the GC samples were characterized by an XRD and transmission electron microscope (TEM). Optical band-gap of the samples was estimated on the basis of diffuse-reflectance spectroscopy (DRS) using a ultraviolet (UV)-visible spectrometer with an attached integrating sphere. Photocatalytic reaction and its activity were assessed on the basis of the degradation of rhodamine-B dye (Rh-B) solution $(3 \mathrm{mg} / \mathrm{L})$ under the irradiated light emitting diode (LED)-UV lamp $(16 \mathrm{~W} ; 312 \mathrm{~nm})$. The obtained GC samples $(40 \mathrm{mg})$ were dispersed in the Rh-B solution $(40 \mathrm{~mL})$. The degradation of Rh-B as a function of time was monitored by means of an UV-visible spectrometer. All of the measurements were performed at room temperature.

The DTA measurement revealed a small endothermal region and three exothermal peaks in the distinct temperature regions, corresponding to the glass-transition $\left(T_{\mathrm{g}}\right)$ and crystallization-peak $\left(T_{\mathrm{p}}\right)$ temperatures, respectively, and their thermal parameters were estimated to be $T_{\mathrm{g}}=$ $443{ }^{\circ} \mathrm{C}$, and $T_{\mathrm{p} 1}=495^{\circ} \mathrm{C}, T_{\mathrm{p} 2}=570^{\circ} \mathrm{C}$ and $T_{\mathrm{p} 3}=627^{\circ} \mathrm{C}$. The exothermal reaction was totally terminated around $670^{\circ} \mathrm{C}$. Therefore, we have prepared the glass samples heat-treated at the $T_{\mathrm{p} 1}, T_{\mathrm{p} 2}, T_{\mathrm{p} 3}$, and $670{ }^{\circ} \mathrm{C}\left(=T_{\mathrm{pf}}\right)$. Hereafter, the precursor glasses heat-treated at $T_{\mathrm{p} 1}, T_{\mathrm{p} 2}, T_{\mathrm{p} 3}$, and $T_{\mathrm{pf}}$ are denoted by the $T_{\mathrm{p} 1^{-}}, T_{\mathrm{p} 2^{-}}, T_{\mathrm{p} 3^{-}}$, and $T_{\mathrm{pf}}$-samples, respectively. Figure 1 shows the results of powder XRD study for the heat-treated samples. The samples indicated the sharp peaks, i.e., crystalline patterns, and the crystallized phase in the $T_{\mathrm{p} 1}$ - and $T_{\mathrm{p} 2 \text {-samples were identified to }}$ $\mathrm{Bi}_{3} \mathrm{NbO}_{7}$ and $\mathrm{Bi}_{5} \mathrm{Nb}_{3} \mathrm{O}_{15}$ phase, respectively, by comparison with corresponding ICDD (\#00-050-0087 and \#01077-3967), indicating that the precursor glass crystallizes the photocatalytic bismuth niobate phases. The XRD results also suggested the transformation of crystallized $\mathrm{Bi}_{3} \mathrm{NbO}_{7}$ phase into $\mathrm{Bi}_{5} \mathrm{Nb}_{3} \mathrm{O}_{15}$ phase as increasing the temperature. In the $T_{\mathrm{p} 3}$-sample, $\mathrm{Bi}_{4} \mathrm{Si}_{3} \mathrm{O}_{12}$ (\#01-080-1596) and $\mathrm{Li}_{2} \mathrm{~B}_{4} \mathrm{O}_{7}$ (\#00-018-0717) phases were confirmed in addition to the $\mathrm{Bi}_{5} \mathrm{Nb}_{3} \mathrm{O}_{15}$ phase. The XRD pattern of the $T_{\mathrm{pf}}$-sample was similar to that of the sample at $T_{\mathrm{p} 3}$, i.e., coexistence of the $\mathrm{Bi}_{5} \mathrm{Nb}_{3} \mathrm{O}_{15}, \mathrm{Bi}_{4} \mathrm{Si}_{3} \mathrm{O}_{12}$, and $\mathrm{Li}_{2} \mathrm{~B}_{4} \mathrm{O}_{7}$ phases, suggesting that the phase transformation/formation almost completed at the temperature higher than the $T_{\mathrm{p} 3}$.

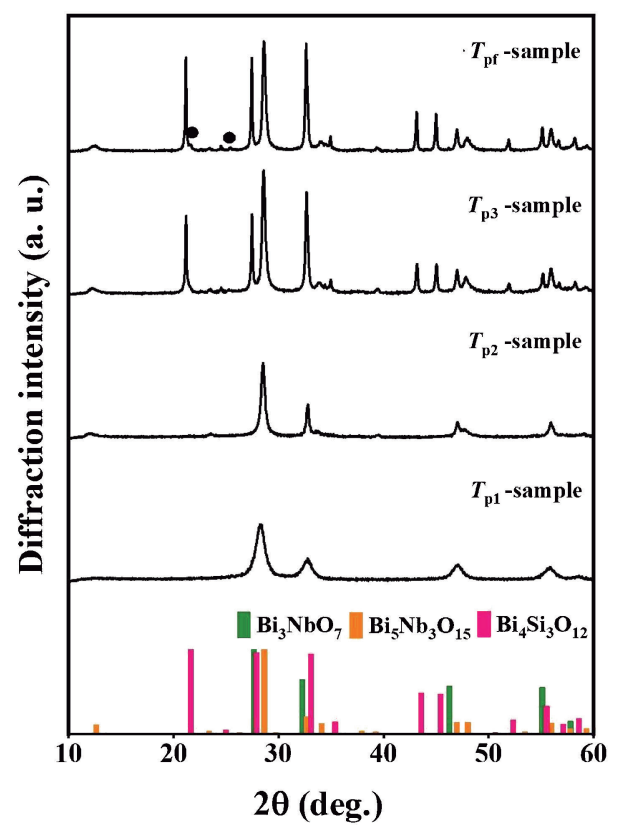

Fig. 1. Powder XRD patterns of the as-quenched glasses subjected to isothermal heat-treatment at different temperatures. The ICDD for the $\mathrm{Bi}_{3} \mathrm{NbO}_{7}$ (\#00-050-0087), $\mathrm{Bi}_{5} \mathrm{Nb}_{3} \mathrm{O}_{15}$ (\#01077-3967), and $\mathrm{Bi}_{4} \mathrm{Si}_{3} \mathrm{O}_{12}$ (\#01-080-1596) are also included. Presence of $\mathrm{Li}_{2} \mathrm{~B}_{4} \mathrm{O}_{7}$ phase (black spot) is indicated on the basis of data (\#00-018-0717).

To investigate the development of internal nanostructure, we have conducted the microscopic observation in the GC samples. Figure 2 shows the TEM results and corresponding electron diffraction (ED) patterns (inset). For the $T_{\mathrm{p} 1}$-sample, in which $\mathrm{Bi}_{3} \mathrm{NbO}_{7}$ phase singly crystallized, we could see the spherical particles with size of $\sim 5 \mathrm{~nm}$ [Fig. 2(a)], and the ED pattern was also identified to be $\mathrm{Bi}_{3} \mathrm{NbO}_{7}$ phase, indicating the nanocrystallization of $\mathrm{Bi}_{3} \mathrm{NbO}_{7}$. In addition, the $T_{\mathrm{p} 2}$-sample $\left(\mathrm{Bi}_{5} \mathrm{Nb}_{3} \mathrm{O}_{15}\right.$ phase crystallized), rectangular nanocrystals with size of $\sim 20$ $30 \mathrm{~nm}$ were observed [Fig. 2(b)]. A selected area electron diffraction (SAED) exhibited the spot-like pattern, suggesting that each nanocrystal has single domain, and are identified to be $\mathrm{Bi}_{5} \mathrm{Nb}_{3} \mathrm{O}_{15}$ phase. Regarding the $T_{\mathrm{p} 3}$ sample, it was notable that the rod-type crystals with size of $\sim 100 \mathrm{~nm}$ are developed [Fig. 2(c)]. The SAED implies that the rod-type nanocrystals are $\mathrm{Bi}_{5} \mathrm{Nb}_{3} \mathrm{O}_{15}$ and $\mathrm{Bi}_{4} \mathrm{Si}_{3} \mathrm{O}_{12}$ phases. Further increasing the treatment temperature, $\left(T_{\mathrm{pf}}\right)$, we could see distinct two regions, i.e., aggregation of the rod-type nanocrystals (dark part) and non-aggregated region (bright part) [Fig. 2(d)]. The bright region was found to be $\mathrm{Li}_{2} \mathrm{~B}_{4} \mathrm{O}_{7}$ phase in accordance with the SAED pattern. Thus, we have successfully fabricated the GCs with photocatalytic nanophases in the $\mathrm{Bi}_{2} \mathrm{O}_{3}-\mathrm{Nb}_{2} \mathrm{O}_{5}-\mathrm{Li}_{2} \mathrm{O}-$ $\mathrm{B}_{2} \mathrm{O}_{3}-\mathrm{SiO}_{2}$ system.

Figure 3 shows the DRS results in the GC samples. We have estimated the optical band-gap on the basis of Tauc's law: $(\alpha h v)^{n}=A\left(h v-E_{\mathrm{g}}\right)$, where $\alpha$ is absorption coefficient, $h$ Planck's constant, $v$ light frequency, $A$ constant, and $E_{\mathrm{g}}$ the band gap. The value of $n$ depends on the characteristic of optical transition, and in this study $n=1 / 2$ 
(a)

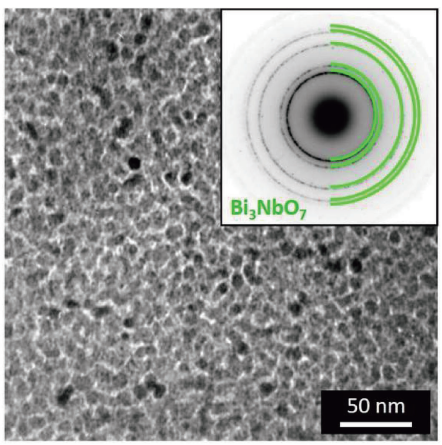

(c)

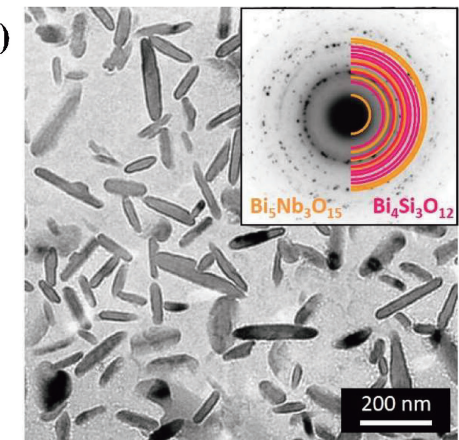

(b)

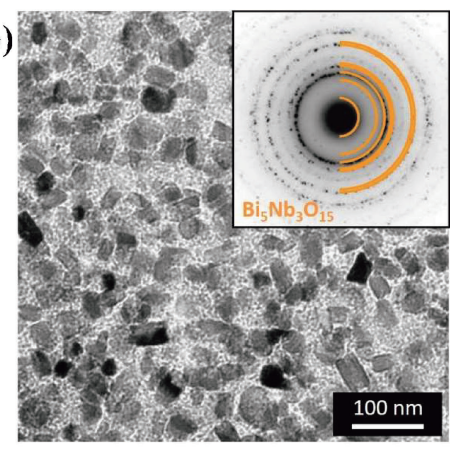

(d)

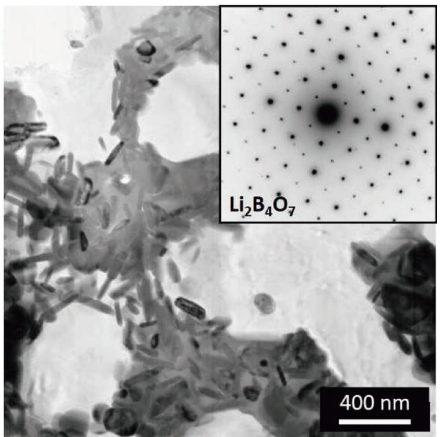

Fig. 2. TEM images and corresponding SAED patterns of the GC samples prepared at $T_{\mathrm{p} 1}=495^{\circ} \mathrm{C}$ (a), $T_{\mathrm{p} 2}=570^{\circ} \mathrm{C}(\mathrm{b}), T_{\mathrm{p} 3}=627^{\circ} \mathrm{C}(\mathrm{c})$, and $T_{\mathrm{pf}}=670^{\circ} \mathrm{C}(\mathrm{d})$. The circles/indices in SAED patterns were indicated on the basis of crystallographic data of $\mathrm{Bi}_{3} \mathrm{NbO}_{7}$ (a), $\mathrm{Bi}_{5} \mathrm{Nb}_{3} \mathrm{O}_{15}$ (b,c), $\mathrm{Bi}_{4} \mathrm{Si}_{3} \mathrm{O}_{12}$ (c), and $\mathrm{Li}_{2} \mathrm{~B}_{4} \mathrm{O}_{7}$ (d).

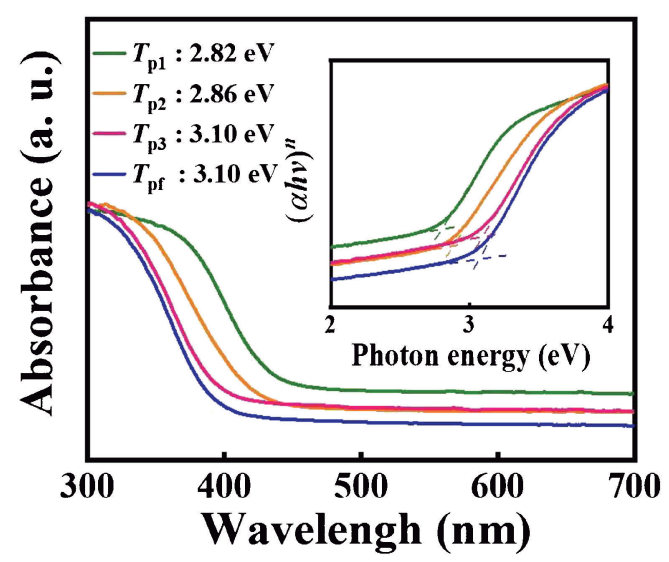

Fig. 3. Diffuse-reflectance spectra of the studied GC samples. The values of band gap $\left(E_{\mathrm{g}}\right)$ were estimated using Tauc's equation (inset).

(indirect transition) was used in accordance with the literatures. ${ }^{15-17)}$ The values of $E_{\mathrm{g}}$ tended to increase with the heat-treatment temperature, i.e., 2.82, 2.86, 3.10, and $3.10 \mathrm{eV}$ for the $T_{\mathrm{p}^{-}}, T_{\mathrm{p} 2^{-}}, T_{\mathrm{p}^{-}}$, and $T_{\mathrm{pf}}$-samples, respectively. The DRS study leads us to expect that the GC samples absorb the photon energy given by LED-UV lamp $(3.97 \mathrm{eV})$ during the photocatalytic assessment.

Figure 4 shows the degradation of Rh-B as a function of time in the studied GC samples. The degradation is represented by ratio of the monitored concentration of $\mathrm{Rh}$ $\mathrm{B}$ to its initial concentration $\left(C / C_{0}\right)$, and the concentrations have been measured by an absorption peak appeared in the range of $500-555 \mathrm{~nm}$. It was found that the all samples exhibit the degradation (or decrease in the values of $C / C_{0}$ ), i.e., the photocatalytic activity [Fig. 4(a)]. The values of $C / C_{0}$ for $300 \mathrm{~min}$ were evaluated to be about 0.58 and 0.75 in the $T_{\mathrm{p} 2^{-}}$and $T_{\mathrm{p} 1}$-samples, respectively. The $T_{\mathrm{p} 3}$-sample involving both $\mathrm{Bi}_{5} \mathrm{Nb}_{3} \mathrm{O}_{15}$ and $\mathrm{Bi}_{4} \mathrm{Si}_{3} \mathrm{O}_{12}$ nanophases possessed the $C / C_{0} \sim 0.05$ for $300 \mathrm{~min}$, indicating the much higher activity, and finally the $T_{\mathrm{p} \text {-sample }}$ could almost decompose the Rh-B within $300 \mathrm{~min}$. Consequently, we have demonstrated the photocatalytic function in the nano-sized $\mathrm{Bi}_{5} \mathrm{Nb}_{3} \mathrm{O}_{15}-\mathrm{Bi}_{4} \mathrm{Si}_{3} \mathrm{O}_{12}$ co-crystallized GCs. To consider the activity of the photocatalytic GCs in detail, we have expressed the data on the basis of firstorder kinetics: $\ln \left(C_{0} / C\right)=k t$, where $k$ and $t$ are rate constant and time, respectively. When the data were replotted in accordance with the equation [Fig. 4(b)], the $T_{\mathrm{p} 1}$ - and $T_{\mathrm{p} 2}$-samples indicated the linear relation between the $\ln \left(C_{0} / C\right)$ and $t$, and subsequently the values of $k$ could be obtained; $k=1.01 \times 10^{-3} \mathrm{~min}^{-1}$ and $k=1.74 \times 10^{-3}$ $\min ^{-1}$ for the $T_{\mathrm{p} 1}$ and $T_{\mathrm{p} 2}$, respectively. Meanwhile, the plots for the $T_{\mathrm{p} 3}$ - and $T_{\mathrm{pr}}$-samples could not be expressed by first order reaction, i.e., the rapid (or nonlinear) increase in the degradation around $200 \mathrm{~min}$.

Thus, the $T_{\mathrm{p} 3^{-}}$and $T_{\mathrm{p} \mathrm{f}^{-}}$-samples, i.e., nano-sized $\mathrm{Bi}_{5} \mathrm{Nb}_{3} \mathrm{O}_{15}-\mathrm{Bi}_{4} \mathrm{Si}_{3} \mathrm{O}_{12}$ co-crystallized GCs, have been demonstrated to show the pronounced photocatalytic activity and its nonlinear behavior as a function of time. Unfortunately, we have no convincing explanation for these features at present. On the other hand, Paul and Giri have reported the similar nonlinear behavior in the timedependence of photocatalytic activity, i.e., rapid increase in the degradation of Rh-B and its deviation from a pseudo 
(a)

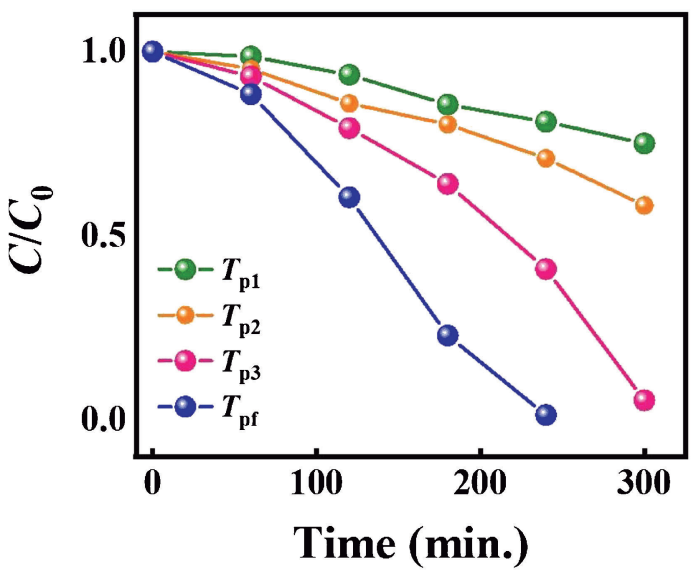

(b)

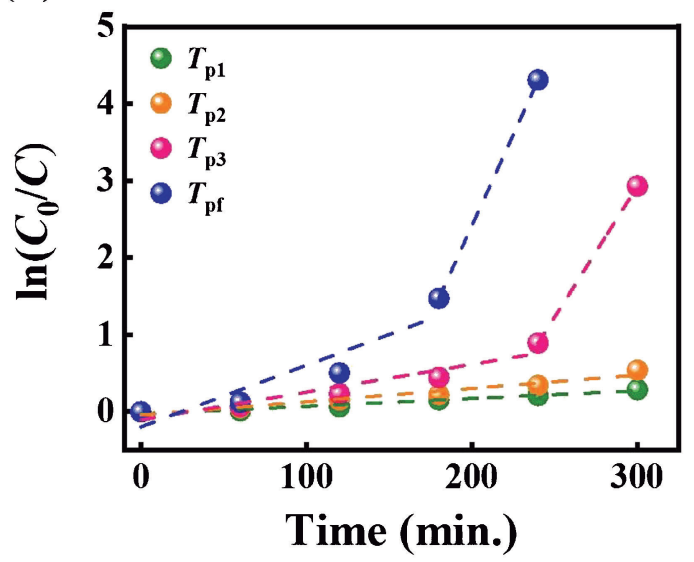

Fig. 4. Results of the Rh-B degradation test: The $C / C_{0}$ as a function of UV-irradiation time (a). $\ln \left(C_{0} / C\right)$ were also plotted (b, see text)

first-order rate kinetics, in nano-photocatalysis consisting of $\mathrm{TiO}_{2}$ attached with $\mathrm{Ag}$ particles. ${ }^{18)}$ In addition, they have suggested that the nonlinear behavior originates in the presence of interface between the $\mathrm{TiO}_{2}$ and $\mathrm{Ag}$, which is able to provide the heterostructure. This leads us to consider that a partial formation of the interface between the $\mathrm{Bi}_{5} \mathrm{Nb}_{3} \mathrm{O}_{15}$ and $\mathrm{Bi}_{4} \mathrm{Si}_{3} \mathrm{O}_{12}$ nanocrystals is possible in the studied $\mathrm{GC}$ materials: The $\mathrm{Bi}_{5} \mathrm{Nb}_{3} \mathrm{O}_{15}$ and $\mathrm{Bi}_{4} \mathrm{Si}_{3} \mathrm{O}_{12}$ nanorods homogeneously distribute in the $T_{\mathrm{p} 3}$-sample, whereas the nanorods closely aggregate in the $T_{\mathrm{p}}$-sample [Fig. 2(d)]. The aggregation possibly provides a suitable condition for contact with the nanorods each other. Since the activity of $T_{\mathrm{pr}}$-sample is much higher than that of $T_{\mathrm{p} 3^{-}}$ sample (Fig. 4), the partial formation of interface (or the heterostructure) between the nanorods may be expected. Indeed, we have studied the reason for the high photocatalytic activity in the co-crystallized sample at present.

Acknowledgements This study was supported by the Ministry of Education, Culture, Sports, Science and Technology of the Japanese Government.

\section{References}

1) K. Wang, Y. Li, G. Zhang, J. Li and X. Wu, Appl. Catal. B-Environ., 240, 39-49 (2019).

2) S. Zhang, Y. Yang, Y. Guo, W. Guo, M. Wang, Y. Guo and M. Huo, J. Hazard. Mater., 261, 235-245 (2013).

3) Z. Wan and G. Zhang, J. Mater. Chem. A, 3, 1673716745 (2015).

4) W. Gu, F. Teng, Z. Liu, Z. Liu, J. Yang and Y. Teng, J. Photoch. Photobio. A, 353, 395-400 (2018).

5) A. Al-Keisy, L. Ren, T. Zheng, X. Xu, M. Higgins, W. Hao and Y. Du, Dalton T., 46, 15582-15588 (2017).

6) S. S. Batool, S. Hassan, Z. Immran, M. A. Rafiq, M. Ahmad, K. Rasool, M. M. Chaudhry and M. M. Hasan, Catal. Commun., 49, 39-42 (2014).

7) K. Yoshida, Y. Takahashi, R. Ihara, N. Terakado, T. Fujiwara, H. Kato and M. Kakihana, APL Mater., 2 , 106103 (2014).

8) K. Yoshida, H. Takahashi, H. Masai, N. Terakado, Y. Takahashi, T. Fujiwara, H. Kato and M. Kakihana, Int. J. Hydrogen Energ., 41, 22055-22058 (2016).

9) Y. Daiko, H. Yajima and T. Kasuga, J. Eur. Ceram. Soc., 28, 267-270 (2008).

10) H. Masai, T. Toda, Y. Takahashi and T. Fujiwara, Appl. Phys. Lett., 94, 151910 (2009).

11) G. Singh, S. Kumar, V. P. Singh and R. Vaish, J. Appl. Phys., 125, 175102 (2019).

12) G. S. Murugan, K. B. R. Varma, Y. Takahashi and T. Komatsu, Appl. Phys. Lett., 78, 4019-4021 (2001).

13) I. G. Kim, J. H. Kim, J. Y. Jung, S. Y. Choi, H. J. Park and B. K. Ryu, J. Ceram. Soc. Jpn., 112, 940-943 (2014).

14) C. G. Baek, Y. H. Rim, J. H. Ko, C. S. Kim and Y. S. Yang, RSC Adv., 10, 14113-14121 (2020).

15) Q. Wang, L. Yuan, M. Dun, X. Yang, H. Chen, J. Li and J. Hu, Appl. Catal. B-Environ., 196, 127-134 (2016).

16) O. Depablos-Rivera, J. C. Medina, M. Bizarro, A. Martínez, A. Zeinert and S. E. Rodil, J. Alloy. Compd., 695, 3704-3713 (2017).

17) A. F. Lima, S. O. Souza and M. V. Lalić, J. Appl. Phys., 106, 013715 (2009)

18) K. K. Paul and P. K. Giri, J. Phys. Chem. C, 121, 20016-20030 (2017). 